\title{
ÖRGÜT KÜLTÜRÜ ÇALIŞMALARININ YÖNTEM VE KAPSAM BAKIMINDAN İNCELENMESI: LİSANSÜSTÜ TEZLER ÜZERİNDEN BİR İNCELEME
}

\author{
Prof. Dr. Rana ÖZEN KUTANIS* \\ Arş. Gör. Emrah ÖZSOY ${ }^{* *}$ \\ Arş. Gör. Ahmet KARAKIRAZ ${ }^{* * * *}$ \\ Arş. Gör. Mustafa ARAS ${ }^{* * * * *}$ \\ Arş. Gör. Emre EROL ${ }^{* * * * * *}$ \\ Arş. Gör. Osman USLU ${ }^{* * * * * * *}$
}

\begin{abstract}
$\ddot{O Z Z}$
Bir bilim dallyla ilgili, belirli aralıklarla yapllacak durum tespiti yararlı olabilmektedir. Bu gerekçe ile bu araştırmada örgüt kültürü alanında yapılmış olan lisansüstü tezler konu ve yöntem bakımindan incelenerek, alanda yapılan çalışmaların mevcut durumunun tespit edilmesi amaçlanmıştır. Araştırma amacına yönelik olarak, erişimine yazar tarafindan izin verilen 146 adet yüksek lisans tezi ve 37 adet doktora tezi olmak üzere toplam 183 adet lisansüstü tez, daha önceden belirlenen bazı boyutlar üzerinden incelenmiştir. Tezlerin, belirlenen boyutların esas alındı̆̆ detaylı incelemesi sonucunda; tipoloji gelişstirme, ölçek geliştirme, boyut gelişstirme, örgüt kültürü çalışmalarının eleştirisi gibi hususlara hemen hemen hiçbir tezde yer verilmediği, yöntem olarak ise çok büyük oranda nicel yöntemlere başvurulduğu, nitel ve karma yöntemlerden ise çok az saylda tezde yararlanıldı̆̆l tespit edilmiştir. Nicel yöntemler kullanılarak yürütülen tezlerde ise çok büyük oranda uluslararası alanda kullanılan ölçeklerin tercih edildiği ve geçerlik ve güvenilirlik analizlerinin bazı çalışmalarda ihmal edildiği belirlenmiştir. İncelenen tezler ışı̆̆ında elde edilen bulgular, alanın sorunlarının büyük oranda süregeldiğini ortaya koymaktadır. Araştırmanın sonunda ise örgüt kültürü alanında çalışan araştırmacılara, bundan sonra yapılacak çalışmalar için önerilerde bulunulmuştur.
\end{abstract}

Anahtar Kelimeler: Örgüt kültürü, Yöntem, Lisansüstü Tezler.

JEL Sinıflandırması: D23, M14

\footnotetext{
* Sakarya Üniversitesi, İşletme Fakültesi, İşletme Bölümü, rkutanis@sakarya.edu.tr

** Sakarya Üniversitesi, İşletme Fakültesi, İşletme Bölümü, eozsoy@sakarya.edu.tr

*** Sakarya Üniversitesi, İşletme Fakültesi, İşletme Bölümü, akarakiraz@ sakarya.edu.tr

**** Sakarya Üniversitesi, İşletme Fakültesi, İşletme Bölümü, maras@sakarya.edu.tr

${ }^{* * * * * *}$ Sakarya Üniversitesi, İşletme Fakültesi, İnsan Kaynakları Yönetimi Bölümü, eerol@sakarya.edu.tr

******* Sakarya Üniversitesi, İşletme Fakültesi, İşletme Bölümü, ouslu@sakarya.edu.tr
} 


\title{
EXAMINING ORGANIZATION CULTURE STUDIES IN TERMS OF METHOD AND SCOPE: AN INQUIRY ON THE GRADUATE THESES
}

\begin{abstract}
It is beneficial to make periodically state evaluation about a branch of science for international and national level. With this reason, in this study it is aimed to make state evaluation of studies in organization culture field by examining graduate theses in respect to subject and method. For this reason totally 183 theses as 146 master and 37 Phd for which permission had been given were examined over some dimensions. When subjects of theses analyzed, it was established that there were almost no study about developing typology, developing scale, developing dimension, criticizing organization culture studies and was established that mostly quantitative techniques were used as method and were slightly benefiting from qualitative and mixed methods. It was also found that in quantitative methods mostly internationally used scales were preferred and in some studies validity and reliability analysis were neglected. Findings obtained in the light of examined theses put forth that issues in field are mostly ongoing. End of the research for further studies, recommended matters on which Turkish researchers should concentrate in organization culture field were specified.
\end{abstract}

Keywords: Organization Culture, Method, Graduate Theses

JEL Classification: D23, M14

\section{GÍRIŞ}

Yönetim ve organizasyon yazınının Türkiye'de gelişim seyrinin ele alındığı pek çok çalışma mevcuttur (Berkman, 1987; Berkman, 2009; Erdemir, 2009; Özen, 2002; Üsdiken ve Erden, 2001; Üsdiken ve Erden, 2002; Üsdiken ve Pasadeos, 1992; Üsdiken vd., 1998). Bu çalışmalar, hem yönetim organizasyon alanındaki akademik çalışmaların mevcut durumunun bir fotoğrafını çekerek gelecekte yapılacak olan çalışmalar için yol göstermekte, hem de alanda yapılmakta olan akademik çalışmalarının eksiklerine işaret ederek alanın gelişimine katkı sağlamaktadır. Yönetim ve organizasyon alanını makro bir şekilde ele alan çalışmalar ve yönetim organizasyon disiplininin alt alanlarını ele alan çalışmalar (Sayılar, 2005; Koç vd., 2013; Köseoğlu vd., 2014; Türker ve Yalçınkaya, 2014) incelendiğinde, alana yönelik bazı eleştirilerin yöneltildiği görülmektedir. Başlıca eleştiriler ise şunlardır; Amerikan yazınındaki kavram ve modellerin olduğu gibi çalışmalara aktarılması (Berkman, 1987; Üsdiken vd., 1998; Özen, 2002), Türkiye'nin sosyo-kültürel bağlamının ihmal edilmesi (Berkman, 1987; Koç vd., 2013), incelenen konuların evrenselliğinin sorgulanmaması (Koç vd., 2013), özgün kuramsal-kavramsal modellerin yer aldığı çalışmaların az olması (Berkman, 1987; Koç vd., 2013), araştırılan konuların derinlemesine ve ayrıntılı bir analizin yapılmaması (Berkman, 1987; Erdem, 2009), yönetsel ve örgütsel olguları açılama gayesinden uzak olunması 
(Özen ve Kalemci, 2009), nitel araştırmalara gereken özenin gösterilmemesi (Erdem, 2009; Özen Kutanis vd., 2007) ve görgül çalışmalar ağırlıkta iken kavramsal çalışmaların yeterli sayıda olmamasıdır (Türker ve Yalçınkaya, 2014; Koç vd., 2013).

$\mathrm{Bu}$ çalışmada ise örgüt kültürü konusunda yapılmış olan lisansüstü tezler, konu ve yöntem açısından incelenerek, bu konuda yapılan çalışmaların mevcut durumunun tespit edilmesi ve örgüt kültürü yazınının eleştirel bir bakış açısıyla ele alınması amaçlanmıştır. Üsdiken ve Pasadeos (1993), gerek evrensel düzeyde gerekse ulusal düzeyde bir bilim dalıyla ilgili belirli aralıklarla yapılacak durum tespitinin yararlı olabileceğini belirtmekte, bu yolla elde edilen bilginin egemen olan eğilimleri anlamak, var olan sorunları ortaya koymak ve bunları giderecek bir tartışma ortamı sağlayacağını ifade etmektedirler. Benzer şekilde Erdemir (2009) de Türkiye'de yönetim alanının gelişiminde içebakışın gerekliliğini vurgulamakta, bu içe bakışın belli aralıklarla yapılmasının, alana yönelik beklentileri ve katkıları gündemde tutacağını ifade etmektedir. Bu bakımdan örgüt kültürü konusunda yürütülen çalışmaların genel görünüşüne ilişkin elde edilecek bulgular, ilerleyen zamanlarda bu konuda yapılacak çalışmalar ve bu konuda çalışan araştırmacılar için önem taşımaktadır.

\section{2. ÖRGÜT KÜLTÜRÜ YAZINININ GENEL GÖRÜNÜMÜ}

Örgüt kültürü konusunda yapılan çalışmaların, uluslararası yazında 1980'li yıllarda ivme kazanmaya başladığı belirtilebilir. Bu dönemde daha çok, konunun epistemolojik tartışmalar üzerine yoğunlaştı̆̆ 1 görülmektedir. 90’lı yıllara gelindiğinde, örgüt kültürü konusunda yöntem ve tipoloji arayışları ön plana çıkmıştır. Günümüzde ise örgüt kültürünün örgütsel davranış alanında en çok araştırılan konulardan biri olduğu görülmektedir (Janićijević, 2011: 70). Örgüt kültürü çalışmalarının uluslararası seyrinin, ulusal temelde de takip edildiği söylenebilir. Nitekim 1998-2008 yılları arasında ulusal yönetim ve organizasyon kongresinde sunulan bildiriler incelendiğinde, bildirilerin yaklaşı yarısı örgüt kültürü konusu dâhilinde ele alınmıştır (Erdem 2009).

Örgüt kültürü araştırmalarında; literatür taraması, gözlem, mülakat, anket, ikincil veri kullanımı gibi belli başlı yöntemler ve veri toplama araçları kullanılmaktadır (Janićijević, 2011). Bu araç ve teknikler esasen nitel ve nicel yöntemler olarak kategorize edilmektedir (Silvia ve Simona, 2013). Buna bağlı olarak örgüt kültürü araştırmalarında iki farklı yaklaşım yer bulmuştur. Bunlardan ilki nesnelci-nicel, ikincisi ise öznelci-niteldir. Nitel yöntemler ortama ilişkin gözlem ya da yüz yüze görüşme yoluyla uygulandığından yorumlayıcı bir bakış açısına ve sübjektif bir değerlendirmeye dayanırken, buna karşın niceliksel yöntemler, daha önceden belirlenmiş kategoriler ve boyutlar kullanılarak ölçümlemeyi gerektirmektedir (Danışman ve Özgen, 2003:96). Bu ayrım ontolojik ve epistemolojik varsayımları açısından iki zıt yaklaşımı ortaya koymaktadır. Her bir yöntemin kendine özgü avantaj ve dezavantajlarından bahsetmek mümkündür (Janićijević, 2011). Hızlı veri elde edilebilmesi ve aynı yöntemleri kullanan diğer çalışmalar ile kıyaslamaya olanak sunması nicel yöntemleri cazip kılarken; ele alınan konuların daha geniş çaplı bir incelemesine olanak vermesi, 
özellikle kültür çalışmaları için önem arz eden değer, inanç ve varsayımların altında yatan faktörleri inceleme imkânı sunması nitel yöntemlerin üstün yanlarını oluşturmaktadır. Ancak bunun yanında nicel ve nitel yöntemler bazı sorunlardan muaf değillerdir. Nicel yöntemler; yoruma çok fazla imkân tanımamaları ve araştırmacıyı genellemeye sevk etmeleri yönüyle eleştiri alırlarken, nitel yöntemler ise sübjektif yorumlara imkân vermesi ve zaman alıcı bir süreç ortaya koyması yönüyle eleştirilmektedir (Yauch ve Steudel, 2003; Janićijević, 2011). Bu noktada araştırmacının seçeceği yöntem araştırma amacı, örneklemin yapısı, araştırmanın kısıtları gibi değişkenlere göre şekillenmelidir. Örgüt kültürü araştırmalarında etik ve emik olmak üzere iki bakış açısından da söz etmek gerekir. Etik araştırmalar çok fazla kültürü belli değişkenler bazında karşılaştırmayı amaçladığ1 için daha çok nicel araştırma yöntemlerinden faydalanır. Emik araştırmalar da araştırmacının bir kültürün içine derinlemesine girerek gözlemlerinden, görüşmelerinden, topladığı diğer verilerinden yararlanarak o kültürü sadece önceden belirlenmiş olan boyutlar bazında değil, tüm detayları ile tanımlamasını amaçlamaktadır. Bu nedenle emik araştırmalar da daha çok nitel araştırma yöntemlerini ya da her iki yöntemi birden kullanır. Rosseau'nun (1990; akt. Danışman ve Özgen, 2003) ifade ettiği gibi örgüt kültürü çalışmalarında metodolojik seçimler araştırmacının eğitimine, yetişmesine, düşünce tarzına ve amacına göre farklılaşabilmektedir. Örgüt kültürü araştırmalarında iki temel yöntemin kullanılmasına ek olarak son yıllarda her iki yöntemin de birlikte kullanılmasının faydalı olabileceği görülmektedir (Yauch, ve Steudel 2003; Janićijević, 2011; Danışman ve Özgen, 2003:96).

Örgüt kültürü konusunda yapılan öncü çalışmalar literatür taraması şeklinde iken, günümüzde anket formları aracılığı ile verilerin elde edildiği ampirik çalışmalar ön plandadır (Silvia ve Simona 2013). Erdem (2009:75) örgütsel davranış disiplininde anket tipi veri toplama araçları ile hızlı tasarlanmış araştırmalar yapma eğiliminin güçlü olduğunu belirtmektedir. Bu durum örgütsel davranış araştırmalarında daha çok nicel yöntemlerin kullanıldığını ortaya koymaktadır. Fakat örgüt kültürü çalışmalarında başvurulacak yöntemin seçimi kritik bir aşamadır. Bu süreçte araştırmacı, araştırmanın altında yatan temel varsayımdan bağımsız hareket etmemeli ve araştırmanın kurgusunu o yönde tasarlamalıdır. Dolayısı ile araştırmanın nitel ya da nicel yöntemin benimsenerek yürütülmesi, araştırmanın temel varsayıma ve amacına bağlı olarak ele alınmalıdır (Morgan ve Smircich, 1980).

Türkiye'de örgüt kültürü konusunda yapılan çalışmalar hızlı bir şekilde artmakla birlikte, söz konusu çalışmaların hangi doğrultuda ve ağırlıklı olarak hangi yöntemle yapıldığına dair yeterli çalışmanın yapılmadığı görülmektedir. Erdem (2009) 1998-2008 yılları arasında Ulusal Yönetim ve Organizasyon Kongrelerinde sunulan bildirileri incelemiştir. Söz konusu çalışma kapsamında değerlendirilen 149 bildiriden 39 adedi örgüt kültürü konusuna aittir. Ancak örgüt kültürü çalışmalarının 2008'den sonra izlediği seyir konusunda bir veriye ulaşılamamıştır. Buna ek olarak, örgüt kültürünün Türkiye'de kapsam ve yöntem açısından genel görüşüne ilişkin detaylı bir çalışma bulunmamaktadır. Nicelik ve nitelik bakımından mevcut verilerin varlığı araştırma kapsam, süreç ve yöntemine ilişkin bilgi sunmamaktadır. Bu gerekçe ile bu araştırmada 1993-2013 yılları arasında 
İşletme Anabilim Dalı bünyesinde yazılmış ve erişim engeli olmayan lisansüstü tezlerin tamamı (YÖK Ulusal Tez Merkezinden ulaş1labilen), kapsam ve yöntem bakımından detaylı bir incelemeye tabi tutulmuştur. Bu sayede örgüt kültürü konusunun hangi farklı değişkenler ile ilişkilendirildiği, örgüt kültürü çalışmalarının hangi doğrultuda ilerlediği ve örgüt kültürü çalışmalarında tercih edilen yöntemin nasıl bir hal aldığı hakkında detaylı bir inceleme yapılarak, alana katkı sağlanmaya çalışılmıştır.

\section{ARAŞTIRMANIN KAPSAM VE YÖNTEMI}

Bu araştırmada Türkiye'de örgüt kültürü konusunda yürütülen lisansüstü tez çalışmalarının kapsam ve yöntem bakımından detaylı bir şekilde incelenmesi amaçlanmıştır. Bu amaca ulaşabilmek için hali hazırda konuya ilişkin yayımlanmış makale, bildiri ve tezlerin incelenmesi gerekmektedir. $\mathrm{Bu}$ çalışmada ise örgüt kültürü araştırmaları sadece tezler üzerinden incelenmiştir. Tez çalışmalarında makale ve bildirilerin aksine sayfa sınırının olmaması, ayrıntılarının en ince detayına kadar okuyucuya iletilmesi (Özsoy vd., 2014) ve özellikle araştırmanın yöntem bölümünün daha kapsamlı ele alınmasından dolayı çalı̧̧manın analiz birimini lisansüstü tez çalışmaları oluşturmaktadır.

Araştırma kapsamında yer alan tezler iki aşamada incelenmiştir. İlk olarak tezler aşağıda yer alan sorulara yanıt aranacak şekilde kapsam açısından incelenmiştir;

- Söz konusu tez çalışmasında örgüt kültürü herhangi bir değişkenle ilişkilendirilmiş mi? Eğer bir değişken ile ilişkilendirilmiş ise bu değişken hangisidir?

- Söz konusu tez çalışmasında, belirli değişkenlerin örgüt kültürüne etkisinden bahsedilmiş mi?

- Söz konusu tez çalışmasında, örgüt kültürünün belirli değişkenlere etkisinden bahsedilmiş mi?

- Söz konusu tez çalışması, bir örgütte örgüt kültürü oluşturmaya yönelik mi?

- Söz konusu tez çalışması, örgüt kültürüne ilişkin yeni bir model öneriyor mu?

- Söz konusu tez çalışması, belirli bir örgütün kültürünün analizine yönelik mi?

- Söz konusu tez çalışmasında, bireylerin örgüt kültürünü nasıl algıladığına yer verilmiş mi?

- Söz konusu tez çalışmasında yeni bir örgüt kültürü boyutu geliştirme çabası var mı?

- Söz konusu tez çalışması, örgüt kültürünü eleştirel bir şekilde ele almış mı?

- Söz konusu tez çalışması yeni bir örgüt kültürü tipolojisi geliştirmeye yönelik mi?

- Söz konusu tez çalışması yeni bir örgüt kültürü ölçeği geliştirmeye yönelik mi?

Araştırmanın ikinci kısmında ise ilgili tez çalışmaları yöntem bakımından incelenmiştir. $\mathrm{Bu}$ doğrultuda incelenen tezler; kullanılan yöntem (nitel, nicel, karma, literatür taraması), kullanılan tipoloji, örgüt kültürü boyutları, kullanılan ölçek, kullanılan ölçeklerin geçerlik ve güvenilirlik 
çalışması, ölçeklerin geçerlilik ve güvenilirlik çalışmasında kullanılan analizler üzerinden betimsel analize tabi tutulmuştur. Tezlerin incelenmesinde kullanılan boyutların belirlenmesinde Üsdiken ve Pasadeos (1992), Özen (2000), Sayılar, (2005), Erdemir, (2008) ve Özsoy vd. (2014)' ten yararlanılmıştır.

\subsection{Verilerin Toplanması}

Araştırma kapsamında incelenecek olan tezler Yükseköğretim Kurulu (YÖK)'ün tez erişim sayfasında (http://tez.yok.gov.tr/UlusalTezMerkezi) yer alan, İşletme Anabilim Dalı bünyesinde ve “Örgüt Kültürü” konusunda yazılmış lisansüstü tezlerinden seçilmiştir. YÖK Ulusal Tez Merkezi internet sayfasında "Örgüt Kültürü" anahtar kelimesi ile yapılan taramada, tezlerin erişim durumu ve anabilim dalı kısıtlaması olmadan Mart 2014 tarihi itibariyle 265 adet yüksek lisans 55 adet doktora tezi olmak üzere toplamda 320 adet lisansüstü tezin sistemde mevcut olduğu saptanmıştır. Ancak erişimine yazar tarafindan izin verilen ve İşletme Anabilim Dalı bünyesinde yapılan 146 adet yüksek lisans ve 37 adet doktora tezi olmak üzere toplamda 183 adet lisansüstü tez bulunmaktadır. $\mathrm{Bu}$ araştırmada söz konusu tezlerin tamamı (183 adet) detaylı incelemeye tabi tutulmuştur.

\subsection{Araştırmanın Kısıtları}

Araştırmanın sadece YÖK Ulusal Tez Merkezi Elektronik Tez Arşivinde erişilebilen, "Örgüt Kültürü” konusunda ve İşletme Anabilim Dalı bünyesinde yapılan lisansüstü tez çalışmalarını kapsaması araştırmanın kısıtını oluşturmaktadır.

\section{BULGULAR}

Bu kısımda 183 adet lisansüstü tezin detaylı analizine ilişkin bulgular sunulacaktır;

Lisansüstü tezler, tez türü bakımından incelendiğinde 146 adet $(\% 79,8)$ yüksek lisans tezi ve 37 adet $(\% 20,2)$ doktora tezinin araştırma kapsamında yer aldığı görülmektedir. Dolayısı ile incelenen tezlerin büyük bir kısmını yüksek lisans tezlerinin oluşturduğu görülmektedir.

Lisansüstü tezler, örgüt kültürü konusunun farklı değişkenler ile ilişkilendirilip ilişkilendirilmemesi durumuna göre incelendiğinde ise 92 adet $(\% 50,3)$ tezde örgüt kültürü konusunun farklı bir değişken ile ilişkilendirildiği, 91 adet $(\% 49,7)$ tezde ise örgüt kültürü konusunun herhangi bir değişken ile ilişkilendirilmediği tespit edilmiştir. İlişkilendirilen değişkenler sıklık hiyerarşisine göre belli ölçüde Tablo-1'de yer almaktadır. Buna göre örgüt kültürü konusu en çok örgütsel vatandaşlık davranış1 $(7 \mathrm{kez})$ ve örgütsel bağlılık (7 kez) değişkeni ile ilişkilendirilmiştir. Bunu takiben örgüt kültürü konusu liderlik (6 kez), öğrenen örgütler (6 kez), mobbing (4 kez), performans (4 kez), bilgi paylaşımı (4 kez), iletişim (4 kez), inovasyon (4 kez), örgütsel adalet (4 kez) değişkenleri ile ilişkilendirilmiştir. Örgüt kültürü konusunun iki ve daha fazla kez ilişkilendirildiği değişkenler Tablo1 'de sunulmuştur. 
Örgüt kültürü konusu ile sadece bir kez ilişkilendirilen değişkenler ise; bilişim teknolojileri yeteneği, bireysel değerler, cinsiyet ayrımcılığı, çatışma yönetimi, çevresel çalkantı, çok uluslu şirketler, davranış bozukluğu belirtileri, duygusal zekâ, EFQM mükemmellik modeli, entelektüel sermaye, farkl11ıkların yönetimi, iç girişimcilik, İKY, iş etiği, iş gören seçim süreci, örgüt iklimi, örgütsel başarı, örgütsel çevre ve yap1, örgütsel değişim, örgütsel girişimcilik, örgütsel güven, örgütsel hafıza, örgütsel özdeşleşme, örgütsel sessizlik, özkendilik, politik davranışlar, psikolojik iklim, TKY, tükenmişlik, yöneticilerin kendilerini geliştirmesi ve zaman yönetimi olarak sıralanmaktadır. 
Tablo 1. İncelenen Tezlerin Türü ve Örgüt Kültürünün İlişkilendirildiği Değişkenlere İlişskin Bulgular

\begin{tabular}{|c|c|c|c|}
\hline Değişken & Kategori & Sıklık & $\%$ \\
\hline \multirow{2}{*}{ Tez Türü } & Yüksek Lisans Tezi & 146 & 79,8 \\
\hline & Doktora Tezi & 37 & 20,2 \\
\hline \multirow{2}{*}{ Örgüt Kültürünün Belli Değişkenler İle İlişkisi } & İlişkilendirilmiş & 92 & 50,3 \\
\hline & İlişkilendirme Yap1lmamış & 91 & 49,7 \\
\hline \multirow{20}{*}{ Örgüt Kültürünün İlişkilendirildiği Değişkenler } & Örgütsel Vatandaşlık Davranışı & 7 & 3,8 \\
\hline & Örgütsel Bağlılık & 7 & 3,8 \\
\hline & Liderlik & 6 & 3,3 \\
\hline & Öğrenen Örgütler & 6 & 3,3 \\
\hline & Y1ldırma (Mobbing) & 4 & 2,2 \\
\hline & Performans & 4 & 2,2 \\
\hline & Bilgi Paylaşımı & 4 & 2,2 \\
\hline & İletişim & 4 & 2,2 \\
\hline & İnovasyon & 4 & 2,2 \\
\hline & Örgütsel Adalet & 4 & 2,2 \\
\hline & İş Tatmini & 3 & 1,6 \\
\hline & Motivasyon & 3 & 1,6 \\
\hline & Toplumsal Kültür & 3 & 1,6 \\
\hline & Personel Güçlendirme & 3 & 1,6 \\
\hline & Entelektüel Sermaye & 2 & 1,1 \\
\hline & İşten Ayrılma Niyeti & 2 & 1,1 \\
\hline & Kariyer & 2 & 1,1 \\
\hline & Kişilik & 2 & 1,1 \\
\hline & Takım Çalışması & 2 & 1,1 \\
\hline & Diğer & & 59,7 \\
\hline
\end{tabular}


Tablo 2. Örgüt Kültürü Çalışmalarının Kapsam Açısından Analizine İlişkin Bulgular

\begin{tabular}{|l|l|l|l|}
\hline \multicolumn{1}{|c|}{ Değişken } & Kategori & Siklık & \multicolumn{1}{c|}{$\%$} \\
\hline \multirow{2}{*}{$\begin{array}{l}\text { Tez çalışmasında örgüt kültürüne ilişkin bir model önerisinde } \\
\text { bulunulmuş mu? }\end{array}$} & Evet & 19 & 10,4 \\
\cline { 2 - 4 } & Hayır & 164 & 89,6 \\
\hline Tez çalışmasında mevcut örgüt kültürünün detaylı analizi & Evet & 27 & 14,8 \\
\hline gerçekleştirilmiş mi? & Hayır & 156 & 85,2 \\
\hline \multirow{2}{*}{ Tez çalışmasında örgüt kültürü algısı ele alınmış mı? } & Evet & 149 & 81,4 \\
\cline { 2 - 4 } & Hayır & 34 & 18,6 \\
\hline \multirow{2}{*}{ Tez çalışmasında yeni bir örgüt kültürü boyutu geliştirilmiş mi? } & Evet & 0 & 0 \\
\cline { 2 - 4 } & Hayır & 183 & 100 \\
\hline Tez çalışmasında örgüt külttürü kavramına yönelik eleştirel bir & Evet & 0 & 0 \\
\cline { 2 - 4 } yaklaşım sergilenmiş mi? & Hayır & 183 & 100 \\
\hline \multirow{2}{*}{ Tez çalışması örgüt kültürü tipolojisi gelişșirmeye yönelik mi? } & Evet & 0 & 0 \\
\cline { 2 - 4 } & Hayır & 183 & 100 \\
\hline \multirow{2}{*}{ Tez çalışması yeni bir örgüt kültürü ölçeği geliştirmeye yönelik mi? } & Evet & 3 & 1,6 \\
\cline { 2 - 4 } & Hayır & 180 & 98,4 \\
\hline
\end{tabular}

İncelenen tezlerin büyük bir çoğunluğunda $(\% 89,6)$ örgüt kültürüne ilişkin yeni bir model geliştirme çabasının olmadığı görülmektedir. Buna ek olarak çoğu tezde $(\% 85,2)$ incelenen örgütün kültürü hakkında detaylı bir analiz yapılmamış, bu örgütlerin kültürleri hakkında detaylı bilgiler okuyucuya sunulmamıştır. Tezlerde genellikle $(\% 81,4)$ çalışanların örgüt kültürünü nasıl algıladığ1 sorusuna yanıt aranmış, mevcut kültürün somut çıktıları belirtilmemiştir. Bu tezlerde ele alınan "örgüt kültürü” olgusunun, çalışanların algılarından oluştuğunu söylenebilir. Türkiye'de gerçekleştirilen tez çalışmalarında yeni örgüt kültürü boyutları geliştirmeye yönelik bir çabanın olmadığı da göze çarpmaktadır. Örneğin, incelenen 183 tezin hiçbirinde yeni bir örgüt kültürü boyutu geliştirme çabasına rastlanmamıştır. Bunun yerine yazında var olan, kabul görmüş boyutlar sıklıkla kullanılmıştır. Bunun yanında “Örgüt Kültürü” konusu hiçbir tezde eleştirel bir şekilde ele alınmamış olup, örgüt kültürünü konusunu eleştiren bir teze rastlanmamıştır. Örgüt kültürü konusunda yapılan tezler, tipoloji ve ölçek geliştirme açısından incelendiğinde de durum farklı değildir. İncelenen 183 tezin hiçbirinde yeni bir tipoloji geliştirme çabasına rastlanmazken, sadece üç adet tezde $(\% 1,6)$ yeni bir örgüt kültürü ölçeği geliştirme çabası tespit edilmiştir. Ancak ölçek geliştirme çabası çok düşük olmasına rağmen $(\% 1,6)$, örgüt kültürü çalışmalarında anket kullanımının oldukça yaygın olduğu da görülmektedir. 
Tablo 3. Örgüt Kültürünün Ölçümünde Kullanılan Ölçekler ve Tezlerde Kullanılan Yöntem Türlerine İlişkin Bulgular

\begin{tabular}{|c|c|c|c|}
\hline & & Tez Adedi (n) & Yüzde (\%) \\
\hline \multirow{19}{*}{ Ölçek } & Cameron ve Quin (1992) & 13 & 21,31 \\
\hline & Denison ve Mishra (1995) & 9 & 14,75 \\
\hline & Hofstede (1980) & 6 & 9,83 \\
\hline & Danışman ve Özgen (2003) & 5 & 8,20 \\
\hline & Haris ve Moran (1987) & 4 & 6,56 \\
\hline & Chang ve Lin (2007) & 2 & 3,28 \\
\hline & Cho (2000) & 2 & 3,28 \\
\hline & Erdem ve İşbaşı (2001) & 2 & 3,28 \\
\hline & Goffee ve Jones (2002) & 2 & 3,28 \\
\hline & Harrison ve Stokes (1992) & 2 & 3,28 \\
\hline & Wallach (1983) & 2 & 3,28 \\
\hline & Beach (1993) & 1 & 1,64 \\
\hline & Cooke ve Lafferty (1989) & 1 & 1,64 \\
\hline & Kreitner ve Kinicki (2001) & 1 & 1,64 \\
\hline & Litwin ve Stringer (1968) & 1 & 1,64 \\
\hline & Lopez ve arkadaşları (2004) & 1 & 1,64 \\
\hline & Ogbonna ve Haris (2000) & 1 & 1,64 \\
\hline & Farklı tipolojilerden yararlanılarak oluşturulmuş tipolojiler & 6 & 9,84 \\
\hline & TOPLAM & 61 & 100 \\
\hline \multirow{5}{*}{ Kullanılan Yöntem } & Nicel & 157 & 85,8 \\
\hline & Nitel & 11 & 6,0 \\
\hline & Karma & 8 & 4,4 \\
\hline & Belirtilmemiş & 7 & 3,8 \\
\hline & TOPLAM & 183 & 100 \\
\hline
\end{tabular}


İncelenen 183 adet lisansüstü tezinden sadece 61 'inde $(\% 33,3)$ bir tipolojinin kullanıldığından bahsedilmiştir. Tezlerde kullanılan tipolojiler detaylı bir incelemeye tabi tutulduğunda ise ortaya çok çeşitli tipolojileri barındıran bir tablo çıkmaktadır. Tezlerde en sık başvurulan tipolojiler sırasıyla Cameron ve Quin (1992), Denison ve Mishra (1995), Hofstede (1980), Danışman ve Özgen (2003), Haris ve Morgan (1987) tipolojileridir. Ancak en sık kullanılan tipoloji 13 adet tezde kullanılan (\%21, 31) Cameron ve Quin (1992) tipolojisidir.

Örgüt kültürü konusunda yapılan tezlerde yöntem olarak sıklıkla $(\% 85,8)$ nicel yöntemlerin tercih edildiği görülmektedir. Sadece 11 adet tezde (\%6) nitel yöntemlerden faydalanılmıştır. Karma yöntemin tercih edildiği tez çalışmalarının oranı ise henüz çok azdır $(\% 4,4)$.

Belirli değişkenlerin örgüt kültürüne etkisini ele alan 17 adet teze $(\% 9,3)$ rastlanmıştır. Örgüt kültürünü etkileyen değişkenler Tablo-4'de görüldüğü üzere çeşitlilik göstermektedir. Liderlik ve örgütsel değerler değişkenleri ikişer kez, diğer değişkenler ise bir kez örgüt kültürünü etkileyen değişkenler olarak ele alınmıştır. Örgüt kültürünün belirli değişkenlere etkisini ele alan 73 adet $(\% 39,9)$ teze ulaşılmıştır. Tablo-4'e göre örgüt kültürünün en çok örgütsel bağl1lığa (12 kez) etkisi araştırılmıştır. Ayrıca örgüt kültürünün; iş tatminine (5 kez), örgütsel performansa (5 kez), inovasyona (4 kez), toplam kalite yönetimine (4 kez), çatışma yönetimine (3 kez), iletişime (3 kez),çalışan verimliliğine (3 kez), mobbinge (3 kez) örgütsel vatandaşlık davranışına (3 kez), takım anlayışına (3 kez), bilgi sistemleri uygulama başarısına (2 kez), iş performansına ( $2 \mathrm{kez}$ ), örgütsel adalete ( $2 \mathrm{kez})$ ve örgütsel öğrenmeye (2 kez) etkisi araştırılmıştır. Bu değişkenlere ek olarak bilgi yönetim süreci, bilişim teknolojileri yeteneği, davranış bozuklukları, ekip kaynak yönetimi, iş değerleri, iş sağlığı ve güvenliği, işten ayrılma eğilimi, kadın çalışanların kariyer gelişimleri, kurumsallaşma, örgütsel başarı, pazarlama yeniliği, personel güçlendirme, politik davranış algılamaları, verimlilik ve zaman yönetimi üzerinde de örgüt kültürünün etkisi birer kez araştırılmıştır. 
Tablo 4. Örgüt Kültürünün Birlikte Ele Alındığı Değişkenler ile İliş̧isine Ait Bulgular

\begin{tabular}{|c|c|c|c|}
\hline Boyutlar & Kategori & Tez Adedi (n) & Yüzde (\%) \\
\hline \multirow{3}{*}{ Belli değişkenlerin kültüre etkisi } & Var & 17 & 9,3 \\
\hline & Yok & 166 & 90,7 \\
\hline & TOPLAM & 183 & 100 \\
\hline \multirow{16}{*}{ Örgüt kültürünü etkileyen değişkenlerin isimleri } & Bilgi ve İletişim Teknolojileri & 1 & 5,8 \\
\hline & Çevresel Çalkantı & 1 & 5,8 \\
\hline & Dönüşümcü Liderlik & 1 & 5,8 \\
\hline & Duygusal Zekâ & 1 & 5,8 \\
\hline & İnsan Kaynakları Yönetimi & 1 & 5,8 \\
\hline & Kurumsallaşma & 1 & 5,8 \\
\hline & Liderlik & 2 & 11,6 \\
\hline & Örgüt Yapısınndaki Değişim & 1 & 5,8 \\
\hline & Örgütsel Değerler & 2 & 11,6 \\
\hline & Özelleștirme & 1 & 5,8 \\
\hline & Personel Güçlendirme & 1 & 5,8 \\
\hline & TKY & 1 & 5,8 \\
\hline & Toplum Kültürü (Hofstede) & 1 & 5,8 \\
\hline & Yerel Sosyo-Kültürel Bağlam & 1 & 5,8 \\
\hline & Yöneticilerin Duygusal Zekâları & 1 & 5,8 \\
\hline & TOPLAM & 17 & 100 \\
\hline \multirow{3}{*}{ Örgüt kültürünün belli değiş̧kenlere etkisi } & Evet & 73 & 39,9 \\
\hline & Hayır & 110 & 60,1 \\
\hline & TOPLAM & 183 & 100 \\
\hline \multirow{17}{*}{ Örgüt kültürünün etkilediği değişkenler } & Örgütsel Bağlllık & 12 & 20,04 \\
\hline & İș tatmini & 5 & 6,80 \\
\hline & Örgütsel Performans & 5 & 6,80 \\
\hline & İnovasyon & 4 & 5,44 \\
\hline & Tky & 4 & 5,44 \\
\hline & Çatışma Yönetimi & 3 & 4,08 \\
\hline & İletişim & 3 & 4,08 \\
\hline & Çalışan Verimliliği & 3 & 4,08 \\
\hline & Mobbing & 3 & 4,08 \\
\hline & Örgütsel Vatandaşlık Davranış1 & 3 & 4,08 \\
\hline & Takım Anlayışı & 3 & 4,08 \\
\hline & Bilgi Sistemleri Uygulama Başarısı & 2 & 2,72 \\
\hline & İș Performans1 & 2 & 2,72 \\
\hline & Örgütsel Adalet & 2 & 2,72 \\
\hline & Örgütsel Öğrenme & 2 & 2,72 \\
\hline & Diğer & 17 & 23,12 \\
\hline & TOPLAM & 73 & 100 \\
\hline
\end{tabular}


Tablo 5. Örgüt Kültürü Tezlerinin Yöntem Açısından İncelenmesine Yönelik Bulgular

\begin{tabular}{|c|c|c|c|}
\hline Değişken & Kategori & Sıklık & $\%$ \\
\hline \multirow{3}{*}{$\begin{array}{l}\text { Çalışmada Kullanılan Ölçeklerin Geçerlilik Çalışması } \\
\text { Yapılması }\end{array}$} & Evet (yap1lmış) & 76 & 42,9 \\
\hline & Hayır (yapılmamış) & 101 & 57,1 \\
\hline & Toplam & 177 & 100,0 \\
\hline \multirow{6}{*}{ Ölçeklerin Geçerliliğinin Tespitinde Kullanılan Analizler } & Faktör Analizi & 70 & 87,5 \\
\hline & İçerik Geçerliliği & 4 & 5,0 \\
\hline & $\begin{array}{l}\text { Çapraz Geçerlilik } \\
\text { (2'ye ayırma) }\end{array}$ & 1 & 1,2 \\
\hline & $\begin{array}{c}\text { Yapısal Eşitlik } \\
\text { Modeli }\end{array}$ & 2 & 2,5 \\
\hline & Uzman Görüşü & 3 & 3,8 \\
\hline & Toplam & 80 & 100,0 \\
\hline \multirow{3}{*}{$\begin{array}{l}\text { Çalışmada Kullanılan Ölçeklerin Güvenilirlik Çalışması } \\
\text { Yapılması }\end{array}$} & Evet & 134 & 74,4 \\
\hline & Hayır & 46 & 25,6 \\
\hline & Toplam & 180 & 100,0 \\
\hline \multirow{3}{*}{$\begin{array}{l}\text { Ölçeklerin Güvenilirliğinin } \text { Tespitinde Kullanılan } \\
\text { Analizler }\end{array}$} & Cronbach's Alpha & 133 & 99,3 \\
\hline & $\begin{array}{c}\text { İkiye Ayırma } \\
\text { Tekniği }\end{array}$ & 1 & 0,7 \\
\hline & Toplam & 134 & 100,0 \\
\hline \multirow{5}{*}{ Kullanılan Ölçeğin Kullanım Ve Hazırlanış Biçimi } & $\begin{array}{l}\text { Hazır ölçek } \\
\text { kullanılmış }\end{array}$ & 101 & 61,2 \\
\hline & $\begin{array}{c}\text { Ölçek literatürden } \\
\text { yararlanarak } \\
\text { derlenmiş }\end{array}$ & 31 & 18,8 \\
\hline & $\begin{array}{c}\text { Yazar kendisi } \\
\text { geliştirilmiş ya da } \\
\text { hazırlanmış }\end{array}$ & 12 & 7,3 \\
\hline & Belirtilmemiş & 21 & 12,7 \\
\hline & Toplam & 165 & 100,0 \\
\hline \multirow{5}{*}{ Çalışmada Uygulanan Nitel Analizler Ve Yöntemler } & Mülakat & 6 & 46,1 \\
\hline & Gözlem & 2 & 15,3 \\
\hline & İçerik Analizi & 4 & 30,7 \\
\hline & Odak Görüşmesi & 1 & 7,6 \\
\hline & Toplam & 13 & 100,0 \\
\hline \multirow{3}{*}{ Çalışma sadece kavramsal açıdan mı ele alınmış? } & Evet & 8 & 4,37 \\
\hline & Hayır & 175 & 95,63 \\
\hline & Toplam & 183 & 100,0 \\
\hline
\end{tabular}

Tezlerde kullanılan 177 ölçeğin 76'sı üzerinde $(\% 42,9)$ geçerlilik analizi uygulandığı, buna karşın 101 adet tezde $(\% 57,1)$ ölçek üzerinde herhangi bir geçerlilik analizi yapılmadığ 1 sonucuna ulaşı1mamıştır. $\mathrm{Bu}$ sonuç ölçeklerin yaklaşık yarısından fazlasının geçerlilik açısından şüpheli olduğunu göstermektedir. Analize tabi tutulan ölçeklerde ise 6 farklı geçerlilik analiz tipinin uygulandığı görülmüştür. Toplamda ölçeklere uygulanan geçerlilik analizi 80 adet olup bunların 62'sini $(\% 77,5)$ faktör analizi, 8'ini (\%10) yapı geçerliliği, 4'ünü (\%5) içerik geçerliliği, 3 'ünü $(\% 3,8)$ uzman görüşü, 2'sini $(\% 2,5)$ yapısal eşitlik modeli ve 1'ini $(\% 1,2)$ çapraz geçerlilik (2'ye ayırma) oluşturmaktadır. Bazı çalışmalarda birden fazla analiz uygulandığı da gözlemlenmiştir. Ölçeklerin geçerliliklerinin tespitinde farklı yöntemler kullanılsa da büyük çoğunluğunda faktör analizinin uygulandığı görülmüştür. Bu sonuç faktör analizinin ölçek geçerliliği tespitinde popüler bir yöntem 
olduğunu göstermektedir. Ölçeklerin güvenilirlik durumuna bakıldığında 180 adet ölçeğin 134'ünün $(\% 74,4)$ güvenilirlik analizine tabi tutulduğu, 46's1 $(\% 25,6)$ için ise herhangi bir güvenilirlik analizi yapılmadığı gözlemlenmiştir. Güvenilirlik tespitinde uygulanan analizlerin neredeyse tümünü $(\% 99,3)$ Cronbach's Alpha oluştururken sadece 1 tanesinin $(\% 0,7)$ ikiye ayırma tekniği olduğu görülmektedir. Cronbach's Alpha katsayısının güvenilirlik tespitinde bilinen ve uygulanan en yaygın yöntem olduğu ifade edilebilir. Tezlerde kullanılan ölçeklerin kullanım ve hazırlanış biçimi incelendiğinde 165 adet ölçeğin 101'inin $(\% 61,2)$ hazır ölçek olduğu, 31'inin $(\% 18,8)$ literatürden yararlanılarak oluşturulduğu, 12'sinin $(\% 7,3)$ yazarın kendisi tarafından geliştirildiği ve kalan 21 'i $(\% 12,7)$ için ise herhangi bir bilgi verilmediği sonucuna ulaşılmıştır.

Tezlerde kullanılan nitel analizler ve yöntemler incelendiğinde 6 kez mülakat $(\% 46,1), 2$ kez gözlem $(\% 15,3), 1$ kez odak görüşmesi $(\% 7,6)$ yönteminden yararlanıldığı ve toplamda 4 kez $(\% 30,7)$ içerik analizi uygulandığı görülmüştür. Son olarak 183 adet tezin sadece 8’inin $(\% 4,37)$ kavramsal olarak ele alındığı ve herhangi bir nicel ya da nitel yöntemden yararlanılmadığı tespit edilmiştir.

Tablo 6. Tezlerde Kullanılan Boyutlara İlişkin Dağılım

\begin{tabular}{|l|l|l|l|}
\hline Boyutlar & Sıklık & Boyutlar & Sıklık \\
\hline Adhokrasi & 20 & Kuralcılık Eğilimi & 5 \\
Klan & 20 & Hiyerarşi Eğilimi & 7 \\
Piyasa & 20 & Klan Eğilimi & Destekleyicilik Eğilimi \\
Hiyerarşi & 20 & Gelişme Eğilimi & 6 \\
Bireycilik/Toplulukçuluk & 17 & Açılık Eğilimi & 5 \\
Güç Mesafesi & 17 & Sonuç Eğilimi & 6 \\
Belirsizlikten Kaçınma & 14 & Takım Eğilimi & 5 \\
Dişillik/Erillik & 11 & Profesyonelizm & 5 \\
Katılım & & & 4 \\
Tutarlılık & 10 & & \\
Adaptasyon Yeteneği & 10 & & \\
Misyon & 10 & & \\
\hline
\end{tabular}

Çalışma kapsamında incelenen tezlerde konu edilen örgüt kültürü boyutları Tablo-6'da dâhil olduğu tipolojiye göre gruplandırılarak verilmiştir. Tablo-6'da görüldüğü üzere en fazla üzerinde durulan boyutlar; adhokrasi, klan, piyasa, hiyerarşi, bireycilik/toplulukçuluk, güç mesafesi, belirsizlikten kaçınma, dişillik/erillik boyutlarıdır. Cameron ve Quin (1992) tipolojisinde bulunan adhokrasi, klan, piyasa ve hiyerarşi boyutları tüm tezlerde beraberce kullanılmalarına rağmen diğer tipolojilerde yer alan boyutların her zaman bir arada kullanılmadığı dikkat çekmektedir.

Ancak bu noktada belirtilmelidir ki incelenen birçok tezde örgüt kültürü boyutlarının literatürde yaygın şekilde kullanılan isimleri yerine başka isimlerin kullanılması ve yapılan faktör analizleri sonucunda boyutların yazarlar tarafından farklı şekillerde isimlendirilmesi, kullanılan ölçeğin ve tipolojinin belirtilmemesi gibi nedenlerle Tablo-6'daki tasnif yalnızca boyut isimlerinin gruplandırmaya izin verecek kadar açıkça yazıldığı tezler esas alınarak yapılmıştır. Tezlerde kullanılan 
boyutların incelenmesi sırasında dikkat çekici bulunan bir diğer nokta da gerçekte örgüt kültürü boyutu olarak tanımlanması güç olan (örneğin liderlik, kendine güven, adalet, iş güvenliği vb.) bir takım kavramların örgüt kültürü boyutu olarak ele alınmaları olmuştur.

\section{SONUÇ}

$\mathrm{Bu}$ çalışmada örgüt kültürü konusunda yapılmış olan lisansüstü tezler, konu ve yöntem açısından incelenmiştir. Bu kapsamda YÖK Ulusal Tez Merkezi internet sitesinde yer alan, İşletme Anabilim Dalı bünyesinde ve örgüt kültürü konusunda yapılmış ve erişimine yazarı tarafindan izin verilen tüm lisansüstü tezler incelenmiştir. Araştırmada ilk olarak tezler kapsam yönünden, daha sonra ise yöntem açısından incelenmiştir. İncelenen tezlerin büyük bir kısmını yüksek lisans tezleri oluşturmaktadır. Tezlerin yaklaşık yarısında örgüt kültürü konusu belirli değişkenler ile ilişkilendirilmiş olup, bu değişkenler kullanım sıklığına göre; örgütsel vatandaşlık, örgütsel bağlılık, liderlik ve öğrenen örgütler şeklindedir.

Tezler kapsam açısından incelendiğinde; tipoloji geliştirme, ölçek geliştirme, boyut geliştirme, örgüt kültürü çalışmalarının eleştirisi gibi hususlarda hemen hemen hiç çalışma yapılmadığı tespit edilmiştir. Öte yandan örgüt kültürüne ilişkin model önerisi, belirli bir örgüt kültürünün analizi ve belirli bir örgüt kültürüne ilişkin algı konularına daha çok yer verilmiştir.

Tezlerde veri toplama aracı olarak anket tekniğinin yoğun olarak kullanıldığı tespit edilmiştir. $\mathrm{Bu}$ bulgu Ulusal Yönetim ve Organizasyon yazınına ilişkin yapılan çalışmalarla (Üsdiken ve Pasadeos, 1992; Özen, 2000; Erdemir, 2008; Yalçınkaya ve Türker, 2014; Özsoy vd., 2014); nitel yöntemlerin az sayıda kullanılması ise Özen Kutanis ve arkadaşlarının (2007) ve Erdem (2008)'in çalışmalarındaki bulgularla paralellik arz etmektedir. Ölçek kullanımında ise araştırmacıların büyük oranda uluslararası alanda geliştirilmiş ve Türkçe'ye uyarlanmış ölçeklere başvurdukları tespit edilmiştir. Ayrıca araştırmacılar Türkçe geliştirilmiş ölçekleri çok az sayıda çalışmada kullanmışlardır. Bununla birlikte çok nadiren araştırmacı ölçeğini kendisi geliştirmiştir ya da literatürden derleyerek oluşturmuştur. Bazı araştırmacıların ise kullandığı ölçeğe ilişkin herhangi bir açıklama yapmadığı tespit edilmiştir. Kullanılan ölçekler analiz edildiğinde ise en çok Cameron ve Quin (1992) tarafindan geliştirilen örgüt kültürü ölçeğinin kullanıldığı tespit edilmiştir. Bunu takiben Denison ve Mishra (1995), Hofstede (1980), Danışman ve Özgen (2003) ve Haris ve Moran (1987) tarafından geliştirilen diğer örgüt kültürü ölçekleri de sık kullanılan ölçekler arasında yer almaktadır.

İncelenen tezlerde çok büyük oranda nicel yöntem izlenmesine rağmen tezlerin yarısından fazlasında geçerlik analizine başvurulmadığı ve geçerlik analizi olarak ise çok büyük oranda sadece faktör analizinden (açıklayıcı faktör analizi) yararlanıldığı tespit edilmiştir. Bununla birlikte nicel yöntemin izlendiği araştırmaların yaklaşık \%75'lik bir kısmına güvenilirlik analizi uygulanmış ve güvenilirlik analizi için çok büyük bir oranda (sadece bir çalışma haricinde) Cronbah's Alfa ( $\alpha$ ) iç tutarlılık testine başvurulmuştur. Dolayısı ile hem geçerlik hem de güvenilirlik analizinde tezlerin 
önemli bir kısmında ilgili analizler ihmal edilmiştir. Geçerlik için büyük oranda sadece faktör analizi güvenilirlik için ise çok büyük oranda yine sadece Cronbah's Alfa $(\alpha)$ iç tutarlılık testi kullanılmışıtır ve harici geçerlik ve güvenilirlik analiz tekniklerine hemen hemen hiç yer verilmemiştir. Bu bulgular Erdemir (2008) ve Özsoy ve arkadaşları (2014) tarafindan yapılan çalışma bulgularını desteklemektedir.

Ulusal Yönetim ve Organizasyon yazınında yapılan benzer çalışmaların bulguları ile bu çalışmanın bulgularının paralellik gösterdiği söylenebilir. Örneğin Berkman’ın (2009: 47-48) 1987 yılında yaptığı çalışmasında; ulusal yazına Amerikan yazınındaki kavramların ve modellerin aktarıldığı, Türkiye'nin sosyo-kültürel bağlamının göz ardı edildiği, araştırılan konuların derinlemesine ve ayrıntılı bir biçimde ele alınmadığı ve özgün kuramsal-kavramsal modellerin yer aldığı çalışmaların az olduğu saptanmıştır. Benzer şekilde Üsdiken ve diğg., (1998) ABD kaynaklı uygulama ve yaklaşımların ulusal yazına ithal edilmiş olduğu belirtilmiştir. Özen (2002) ise yönetim organizasyon alanında yapılan çalışmaların törensel görgülcülük anlayışı içinde gerçekleştirildiği üzerinde durmuştur (Özen, 2002: 12). Bunun yanı sıra Özen ve Kalemci’nin (2009: 80) çalışmasında, Türkiye'deki gelenekselleşmiş yaklaşımın örgütsel/yönetsel olguları "anlamak" veya "açıklamak" gayesinden uzak oluşu saptamasında bulunulmuştur. Buna paralel olarak Erdem (2009) çalışmasında örgüt kültürünün yönetim ve organizasyon alanında giderek yaygınlaşan bir çalışma alanı olduğunu, ancak alanda ilerlemenin gecikmeli gerçekleştiğini ve ağırlıklı olarak nicel araştırma yöntemlerine başvurulduğunu tespit etmiştir.

Ulusal ve uluslararası alanda yaygın bir şekilde çalışılan örgüt kültürü konusunda Türkiye'de de çok sayıda çalışma yapılmaktadır. Ancak incelenen tezlerden elde edilen bulgular, alanın sorunlarının büyük oranda süregeldiğini ortaya koymaktadır. Bu sebeple araştırma kapsamında elde edilen bulgular 1şığında araştırmacıların örgüt kültürü konusunda bundan sonra yapılacak çalışmalarda üzerinde yoğunlaşması önerilen hususlar şunlardır;

- Örgüt kültürü konusunun karmaş1k doğası gereği sadece nicel yöntemlerle değil, bunun yanında nitel yöntemlerle çalışılmasına da ağırlık verilmesi,

- Son dönem örgüt kültürü çalışmalarında görülmeye başlanan karma yöntemlerin kullanımına ağırlık verilmesi,

- Ulusal bazda yürütülen örgüt kültürü araştırmalarında tipoloji geliştirme çalışmalarına ve eleştirel çalışmalara yer verilmesi,

- Uluslararası alanda yaygın bir şekilde kullanılan ölçeklerin eleştirilmeden ve uyumlaştırılmadan, doğrudan araştırmalarda kullanılmaması hususunda çaba harcanması,

- Araştırmacıların kullandığı ölçeklerin, araştırma örneklemine ve amacına uygunluğunun sinanmas1,

- Ulusal yazında kullanılabilecek özgün ölçeklerin geliştirilmesine çaba harcanması, 
- Araştırmalarda kullanılan ölçeklerin geçerlik ve güvenilirlik analizlerine yer verilmesi ve bu hususta madde analizi, doğrulayıcı faktör analizi, ölçüt geçerliği gibi diğer önemli geçerlik ve güvenilirlik analizlerinin de kullanılması,

- Araştırmacıların kullanıldığı ölçekleri nasıl seçtikleri ya da geliştirdiklerini çalışmalarında açık bir şekilde belirtmeleri,

Sonuç olarak bu çalışmada örgüt kültürü konusunda yapılmış ve erişimine izin verilen 183 adet lisansüstü tez çalışması incelenmiştir. Genel olarak doktora tezlerinin yöntem kısımları, bilimsel araştırma sürecinde izlenmesi gereken süreçlere büyük oranda uyum gösterse de kapsam açısından yapılan analizlerde önemli eksiklikler tespit edilmiştir.

\section{KAYNAKÇA}

Beach, L. R. (1993) "Making the right decision: Organizational culture, vision, and planning", Englewood Cliffs, N.J: Prentice Hall.

Berkman, A. Ü. (1987) “Amme İdaresi Dergisi'nde Yayınlanan Makaleler ve Türk Yönetim Bilimi”, Amme İdaresi Dergisi, 20 (4): 19-42.

Berkman, A. Ü. (2009) “Amme İdaresi Dergisi'nde Yayınlanan Makaleler ve Türk Yönetim Bilimi”, Eskişehir Osmangazi Üniversitesi İ.̇̇.B.F. Dergisi, 4(1): 25-49.

Cameron K. S. ve Quinn, R. S. (1992) "Diagnosing and Changing Organizational Culture", Massachusetts: Adison-Wesley.

Chang, S. E. ve Lin, C.-S. (2007) "Exploring organizational culture for information security management", Industrial Management \& Data Systems, 107(3): 438-458.

Cho, H. J. (2000). The Validity and Reliability of the Organizational Culture Questionnaire, www.denisonculture.com, (08.04.2014)

Cooke, R.A., ve Lafferty, J.C. (1989) “Organizational Culture Inventor", Plymouth: Human Synergistics

Danışman, A. ve Özgen, H. (2003) “Örgüt Kültürü Çalışmalarında Yöntem Tartışmasıı:NitelikselNiceliksel Yöntem İkileminde Niceliksel Ölçümler ve Bir Ölçek Önerisi”, Yönetim Araştırmaları Dergisi, 3(2): 91-124.

Denison, D. R. ve Mishra, A. K. (1995) "Towards a theory of organizational culture and effectiveness", Organizational Science, 6(2): 204-223

Erdem, F. ve Özen-İşbaş1, J. (2001) "Eğitim kurumlarında örgüt kültürü ve öğrenci alt kültürünün alg1lamaları", Akdeniz İ.İ.B.F. Dergisi, 1:33-57. 
Erdem, F.(2009) "Örgütsel Davranış Araştırmalarında Niş Alanlar Nasıl Belirleniyor? Ulusal Yönetim ve Organizasyon Kongresi Yazını Üzerine Kısa Bir Değerlendirme”, Eskişehir Osmangazi Üniversitesi İ.İ.B.F. Dergisi, 4(1):65-78.

Erdemir, E. (2008) "Yönetim ve Örgüt Araştırmalarında Ölçek Kullanımı: Yönetim Organizasyon Kongre Bildiri Örneği”, 16. Ulusal Yönetim ve Organizasyon Kongresi, 16-18 Mayıs, İstanbul Kültür Üniversitesi, Antalya.

Erdemir, E. (2009) “Türkiye’de Yönetim/Örgüt Alanının Gelişimi”, Eskiş̧ehir Osmangazi Üniversitesi İİBF Dergisi, 4(1): 7-12.

Goffee, R., ve Jones, G. (2002) "The character of a corporation: How your company's culture can make or break your business". London: Profile Books.

Haris, P. R. ve Moran, R. H. (1987) “Managing Cultural Differences”, Houston: Gulf Publishing.

Harrison, R., ve Stokes, H. (1992) “Diagnosing organizational culture”, Amsterdam: Pfeiffer \& Co.

Hofstede, G. (1980) “Culture' s Consequences”, London : Newbury Park.

Janićijević, N. (2011) "Methodological approach in the research of organizational culture" 69. Economic Annals, LVI (189): 69-99.

Koç, U., Türker, Y. ve Özcan, H. M. (2013) “Çevre'deki Bilim: Türkiye'deki İnsan Kaynakları Yönetimi Araştırmaları”, 21. Ulusal Yönetim ve Organizasyon Kongresi, Kütahya

Köseoğlu, M. A., Akdeve, E. ve Karayormuk, K. (2014) "Stratejik Yönetim Araştırmalarında Hangi Yöntem(ler) Uygulanıyor? Lisansüstü Tezler Üzerinden Bir Araştırma”, 22. Ulusal Yönetim ve Organizasyon Kongresi, Konya

Kreitner, R., ve Kinicki, A. (2001) “Organizational behavior”, Boston, Mass: Irwin/McGraw-Hill.

Litwin, G., ve Stringer, R. (1968) "Motivation and organizational climate", Division of Research Graduate School of Business Administration, Printed United States of America, Boston: 29146.

López, S. P., Peón, J. M. M., ve Ordás, C. J. V. (2004) "Managing knowledge: the link between culture and organizational learning", Journal of Knowledge Management, 8 (6):93-104.

Morgan, G., ve Smircich, L. (1980) “The case for qualitative research”, Academy of Management Review, 5: 491-500.

Ogbonna, E., ve Harris, L. (2000) "Leadership style, organizational culture and performance: empirical evidence from UK companies", The International Journal of Human Resource Management, 11 (4): 766-788. 
Özen Kutanis, R., Bayraktaroğlu, S. ve Yıldırım, E. (2007) "Nitel Araştırmanın Dayanılmaz Hafifliği2: İdealler ve Gerçekler”, 15. Ulusal Yönetim ve Organizasyon Kongresi, Sakarya

Özen, Ș. (2000) “Türk Yönetim/Organizasyon Yazınında Yöntem Sorunu: Kongre Bildirileri Üzerine Bir İnceleme”, DAÜ Turizm Araştırmaları Dergisi, 1(1): 89-118.

Özen, Ş. (2002) “Türkiye'deki Örgütler/Yönetim Araştırmalarında Törensel Görgülcülük Sorunu”, Yönetim Araştırmaları Dergisi, 2(2): 5-31.

Özen, Ş., ve Kalemci, A. (2009) “Ulusal Yönetim ve Organizasyon Konresi’nin Doğuşu, Kurumsallaşması ve Alana Etkileri”, Eskişehir Osmangazi Üniversitesi İ.İ.B.F. Dergisi, 4(1): 79-112.

Özsoy, E., Uslu, O., Karakiraz, A. ve Aras, M. (2014) "İş Tatmininin Ölçümünde Ölçek Kullanımı: Lisansüstü Tezler Üzerinden Bir İnceleme", İşletme Araştırmaları Dergisi, 6(1): 232-250

Sayılar, Y. (2005) “İnsan Kaynakları Yönetimi Alanının Türkiye'deki Gelişim Çizgisi: Yönetim Organizasyon Kongreleri Üzerine Bir Araştırma”, Eskişehir Osmangazi Üniversitesi Sosyal Bilimler Dergisi, 6: 147-176.

Silvia, D. ve M. M. Simona. (2013). Research methods used in analyzing Organizational culture. http://fse.tibiscus.ro/anale/Lucrari2013/Lucrari_vol_XIX_2013_069.pdf (05.04.2014)

Türker, Y. ve Yalçıkaya, A. (2014) “Türk Yönetim/Örgüt Yazınında Örgüt Kuramı Çalışma Alanı: 2002-2013 Yı1ları Arası Kongre ve Çalıştay Bildirileri Üzerine Bir Değerlendirme” 22. Ulusal Yönetim ve Organizasyon Kongresi, Konya.

Üsdiken, B. ve Erden, Z. (2001) “Örnek Alma, Mecbur Tutulma ve Geçmişe Bağımlılık: Türkiye'deki Yönetim Yazınında Değişim”, Amme İdaresi Dergisi, 34(4): 1-31.

Üsdiken, B. ve Erden, Z. (2002) “1990’lı Yıllarda Türkiye’de Yönetim Alanı: Disiplin Yapısı ve Yaklaşımlar”, Yönetim Araştırmaları Dergisi, 2(1): 91-112.

Üsdiken, B. ve Pasadeos, Y. (1992) “Türkiye'de Yayınlanan Yönetimle İlgili Veri Temelli Makalelerde Yöntem”, ODTÜ Gelişme Dergisi, 19(2): 249-266.

Üsdiken, B. ve Pasadeos, Y. (1993) “Türkiye'de örgütler ve yönetim yazını”, Amme İdaresi Dergisi, 26(2): 73-93.

Üsdiken, B., Selekler, S. ve Çetin, D. (1998) “Türkiye'de Yönetim Yazınına Egemen Anlayışın Oluşumu: Sevk ve İdare Dergisi Üzerine Bir İnceleme. Amme İdaresi Dergisi”, 31(1): 57-87.

Wallach, E. J. (1983) “Individuals and Organizations: The Culture Match", Training and Development Journal, 2: 29-36. 
Yauch, C. ve Steudel, H. (2003) "Complementary Use of Qualitative and Quantitative Cultural Assessment Methods", Organizational Research Methods, 6(4): 465-481. 